RSV-Bronchiolitis

\title{
Mütterliche Herdimmunität schützt Säuglinge
}

Stensballe LG et al. Seasonal Variation of Maternally Derived Respiratory Syncytial

Virus Antibodies and Association with Infant Hospitalizations for Respiratory

Syncytial Virus. J Pediatr. 2009;154:296-298

\section{Hintergrund}

Bei Frühgeborenen erhöht ein inkompletter Transfer mütterlicher neutralisierender Antikörper gegen das Respiratory Syncytial Virus (RSV) das Risiko für schwere RSV-Infektionen. Die passive Gabe polyklonaler oder humanisierter monoklonaler Antikörper gegen RSV führt zu einer Reduktion von RSV-Infektionen der unteren Atemwege und der Krankenhausaufnahmen von Frühgeborenen und Kindern mit chronischen Lungenerkrankungen.

In gemäßigten Klimaregionen treten Epidemien mit RSV-Infektionen der unteren Atemwege bei Säuglingen und Kleinkindern im späten Herbst, im Winter und im frühen Frühjahr auf. Im tropischen oder semitropischen Klima treten ebenfalls regelmäßig RSV-Epidemien auf, aber mit anderen saisonalen Mustern.

\section{Fragestellung}

Warum haben RSV-Infektionen bei Säuglingen unter sechs Lebensmonaten eine sehr starke Jahreszeiten-Abhängigkeit?

\section{Methodik}

In Dänemark wurden 459 prospektiv gesammelte Nabelschnurblutproben bezüglich einer Assoziation zwischen der Konzentration an RSV neutralisierenden Antikörpern, die von der Mutter an das Neugeborene übertragen wurden, und der Krankenhausaufnahmen wegen einer RSV-Infektion untersucht.

\section{Ergebnisse}

Es fand sich eine klare zeitliche Assoziation (Abb. 1). Hohe Titer an RSVneutralisierenden Antikörpern waren umgekehrt proportional zur Inzidenz von akuten RSV-Infektionen der un- teren Atemwege während der ersten sechs Lebensmonate.

Sobald der mittlere Nabelschnur-RSVAntikörpertiter (ausgedrückt als $\log _{2}$ ) unter 7,5 (d.h. < 1:181) fiel, nahm die Zahl der wegen RSV-Infektionen hospitalisierten Säuglinge unter sechs Lebensmonaten steil zu. Die RSV-Infektionen in der Säuglingspopulation setzten sich für etwa drei Monate fort, nämlich solange, bis die mütterlichen Antikörperspiegel (durch mütterliche RSV-Infektionen) wieder angestiegen und die meisten Säuglinge wieder geschützt waren. Sobald also unter den Müttern eine Herdimmunität entstanden ist, sinkt die Infektionsrate bei den Säuglingen, und es kommt nachfolgend zu einer Abnahme der Krankenhausaufnahmen.
Auch wenn der mütterliche Antikörperspiegel später wieder abfiel, erschienen die Neugeborenen in den nächsten sechs Monaten ausreichend geschützt, nämlich so lange, bis der mittlere RSVAntikörperspiegel wieder unter 7,5 fiel und ein neuer Zyklus begann. Sobald also in einer Population die Zahl der Kinder mit kritisch niedrigen Titern steigt, kann eine Epidemie mit RSV entstehen.

\section{Kommentar}

Prof. Dr. med.

Matthias Griese, München

1. Mütter sind durch ihre Kinder wahrscheinlich mehr als die allgemeine Population RSV-exponiert. Eine RSV-Immunisierung Schwangerer könnte die Zahl der Krankenhausbehandlungen wegen RSV erniedrigen.

2. Die zyklische Abhängigkeit des Musters an RSV-neutralisierenden Antikörpern und der RSV-Saisonalität sind ein wichtiger Teil der Erklärung der periodischen RSV-Epidemien in den gemäßigten Klimazonen.

\section{Titer der RSV neutralisierenden Antikörper und} Hospitalisierungen aufgrund von RSV-Infektionen

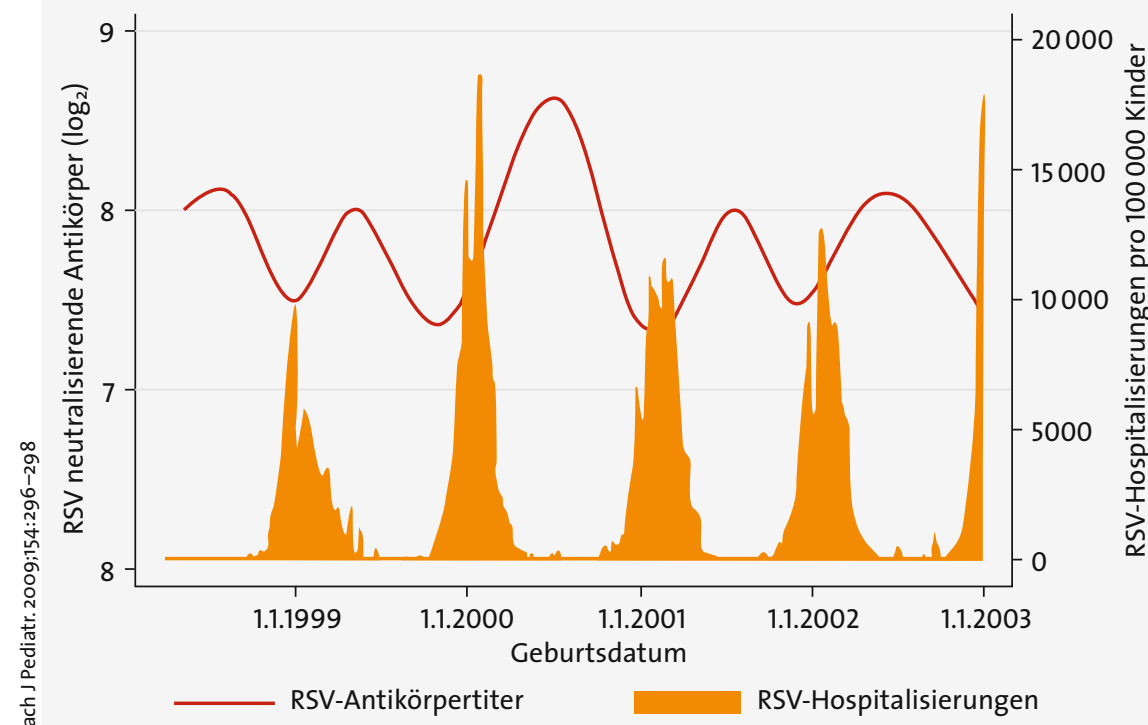

Der zeitliche Zusammenhang ist offensichtlich: Säuglinge, die im Sommer geboren sind, wenn Mütter hohe Antikörperspiegel haben, erkranken seltener an RSV-Infektionen. 